\title{
Thermal Stability and Tribological Performance of DLC-Si-O Films
}

\author{
Nutthanun Moolsradoo, Shinya Abe, and Shuichi Watanabe \\ Department of Systems Engineering, Nippon Institute of Technology, 4-1 Gakuendai, Miyashiro Machi, Saitama 345-8501, Japan \\ Correspondence should be addressed to Nutthanun Moolsradoo, nutthanun.moo@kmutt.ac.th
}

Received 13 June 2011; Accepted 22 August 2011

Academic Editor: Paul Munroe

Copyright (c) 2011 Nutthanun Moolsradoo et al. This is an open access article distributed under the Creative Commons Attribution License, which permits unrestricted use, distribution, and reproduction in any medium, provided the original work is properly cited.

\begin{abstract}
The thermal stability and tribological performance of silicon- and oxygen-incorporated diamond-like carbon films were investigated. The DLC-Si-O films were deposited using plasma-based ion implantation (PBII) method. The deposited films were annealed at $400^{\circ} \mathrm{C}, 600^{\circ} \mathrm{C}$, and $750^{\circ} \mathrm{C}$ for 1 hour in vacuum, in argon, and in air atmospheres. Film properties were investigated using the Fourier transforms infrared spectroscopy, Raman spectroscopy, energy dispersive X-ray spectroscopy, and a ball-on-disk friction tester. The structures of the DLC-Si-O films with a low Si content ( $\leq 25$ at. $\% \mathrm{Si}, \leq 1$ at. $\% \mathrm{O})$ and high Si content $(>25$ at. $\% \mathrm{Si}$, $>1$ at.\%O) were not affected by the thermal annealing in vacuum at $400{ }^{\circ} \mathrm{C}$ and $600{ }^{\circ} \mathrm{C}$, respectively, while they were affected by thermal annealing in argon and in air at $400^{\circ} \mathrm{C}$. Film with 34 at. $\% \mathrm{Si}$ and 9 at.\%O after annealing demonstrated almost constant atomic contents until annealing at $600^{\circ} \mathrm{C}$ in vacuum. The friction coefficient of DLC-Si-O films with 34 at.\%Si and 9 at. $\% \mathrm{O}$ was shown to be relatively stable, with a friction coefficient of 0.04 before annealing and 0.05 after annealing at $600^{\circ} \mathrm{C}$ in vacuum. Moreover, the low friction coefficient of film annealed at $600^{\circ} \mathrm{C}$ in vacuum with 34 at. $\% \mathrm{Si}$ and 9 at. $\% \mathrm{O}$ was corresponded with low wear rate of $1.85 \times 10^{-7} \mathrm{~mm}^{3} / \mathrm{Nm}$.
\end{abstract}

\section{Introduction}

Diamond-like carbon (DLC) coatings are metastable amorphous films that exhibit unique combinations of properties such as high hardness and elastic modulus, low friction coefficients, optical transparency, good wear resistance, and excellent corrosion resistance. Hence, these films are commonly applied as wear-resistant protective coatings in magnetic storage, automobiles, tooling, and biomedical applications [1-3]. Methods for creating DLC films include magnetron sputtering deposition (MSD), ion beam-assisted deposition (IBAD), plasma-assisted chemical vapor deposition (PACVD) or plasma-enhanced chemical vapor deposition (PECVD), and plasma-based ion implantation (PBII) [4-7]. However, DLC films have several known limitations. Depending on the environment, the films can have a poor friction coefficient and limited friction endurance, as well as low adhesion between the film and substrate due to high intrinsic compressive stress. Furthermore, DLC films have low thermal stability at higher working temperatures. It has been reported that DLC films maintain stable properties up to approximately $400^{\circ} \mathrm{C}$; the graphitization process of the samples starts at this temperature, as revealed by the increasing ratio of $D$ and $G$ peaks of the Raman spectra [8]. Silicon incorporation into DLC has been proven to overcome some of the stated drawbacks, including low intrinsic compressive stress, good adhesion, and mechanical resistance [9]. When both silicon and oxygen are incorporated into DLC films, substantial structural modifications occur. Other authors claim to have obtained a material that consists of an atomic-scale composite of random networks of carbon and silicon in which the carbon network is stabilized by hydrogen and the silicon network is stabilized by oxygen. Silicon-oxide-containing DLC presents interesting mechanical, tribological, and optical properties as well as higher thermal stability and fracture toughness [10]. In earlier studies by Choi et al. [11], the properties of films with a high Si content (29 at.\%) annealed at $500^{\circ} \mathrm{C}$ in air exhibited a high friction due to creation of cracks on the worn surface. In [12] by Venkatraman et al., the wear rate of 
the films was low and drastically increased to $10^{-6} \mathrm{~mm}^{3} / \mathrm{Nm}$ after annealing in air at $400^{\circ} \mathrm{C}$ and $500^{\circ} \mathrm{C}$. The film with 17.3 at.\% Si exhibited friction properties of 0.05 and $>0.2$ after annealing in air at $500^{\circ} \mathrm{C}$ and $600^{\circ} \mathrm{C}[13]$.

Plasma-based ion implantation (PBII), also known as plasma immersion ion implantation (PIII), was initially developed by Conrad and Castagna [14]. PBII was developed to improve the properties of DLC films [15]. In this method, samples are immersed in plasma and biased to a negative potential. A plasma sheath then forms, and accelerated ions bombard the exposed surface of the samples. This is a relatively new method that has been shown to be effective for surface modification [16]. Additionally, the unique advantages of PBII include a low working temperature of less than $100^{\circ} \mathrm{C}$. This low working temperature avoids film quality degradation, such as loose and rough surface structure, and avoids DLC graphitization caused by normal chemical vapor deposition and plasma laser deposition, which are performed at higher working temperatures [17]. Additionally, PBII has a high ion energy (implanting voltage), which is helpful for transferring $\mathrm{sp}^{2}$ bonds to $\mathrm{sp}^{3}$ bonds and creating DLC films rich in $\mathrm{sp}^{3}$ bonds with high hardness and good tribological properties [18].

In this paper, plasma-based ion implantation (PBII) was utilized to prepare DLC-Si-O films using acetylene $\left(\mathrm{C}_{2} \mathrm{H}_{2}\right)$, TMS $\left(\mathrm{C}_{4} \mathrm{H}_{12} \mathrm{Si}\right)$, and oxygen $\left(\mathrm{O}_{2}\right)$ as precursors. The deposition was performed as a function of the $\mathrm{C}_{2} \mathrm{H}_{2}$ : TMS : $\mathrm{O}_{2}$ ratio at a deposition pressure of 2-6 Pa. The aim of the study was to investigate the effects of silicon and oxygen contents on the thermal stability and tribological performance by using annealing temperatures of $400-750^{\circ} \mathrm{C}$ in vacuum, in air, and in argon atmospheres. Film properties were investigated by the Fourier transforms infrared (FT-IR) spectroscopy, the Raman spectroscopy, energy dispersive X-ray spectroscopy, and a ball-on-disk friction tester.

\section{Experimental Details}

A schematic of the PBII apparatus used for the deposition of DLC-Si-O films on silicon wafer was previously shown [19]. Si (100) wafers, $0.7 \mathrm{~mm}$ thick, were used as substrates. The wafers were sputter cleaned with $\mathrm{Ar}^{+}$for $20 \mathrm{~min}$ to remove surface contaminants and surface oxides using a bias voltage of $-10 \mathrm{kV}$. Using a bias voltage of $-20 \mathrm{kV}$, the DLC film interlayer was first deposited with $\mathrm{CH}_{4}$ for $60 \mathrm{~min}$ to improve the adhesion between the film and the substrate. The DLC-Si-O films were deposited from gaseous mixtures of $\mathrm{C}_{2} \mathrm{H}_{2}$ : TMS : $\mathrm{O}_{2}$ (acetylene, tetramethylsilane $\left(\mathrm{C}_{4} \mathrm{H}_{12} \mathrm{Si}\right.$ ), and oxygen) at five different ratios: $14: 1: 2,28: 1: 2,46: 1: 2$, $67: 1: 2$, and $89: 1: 2$. The gas flows of TMS and $\mathrm{O}_{2}$ were kept constant at 1 and $2 \mathrm{sccm}$, respectively. The deposition pressure was set to $2-6 \mathrm{~Pa}$, and total deposited thickness of all films was approximately $500 \mathrm{~nm}$. The bias voltage was set to $-5 \mathrm{kV}$, at an RF power of $300 \mathrm{~W}$. The pulse frequency was set to $1 \mathrm{kHz}$ at a pulse width of $5 \mu$ s and a pulse delay of $25 \mu \mathrm{s}$. The pure DLC film was also deposited on Si substrate using $\mathrm{C}_{2} \mathrm{H}_{2}$ gas by the same deposition process at $2 \mathrm{~Pa}$ deposition pressure.

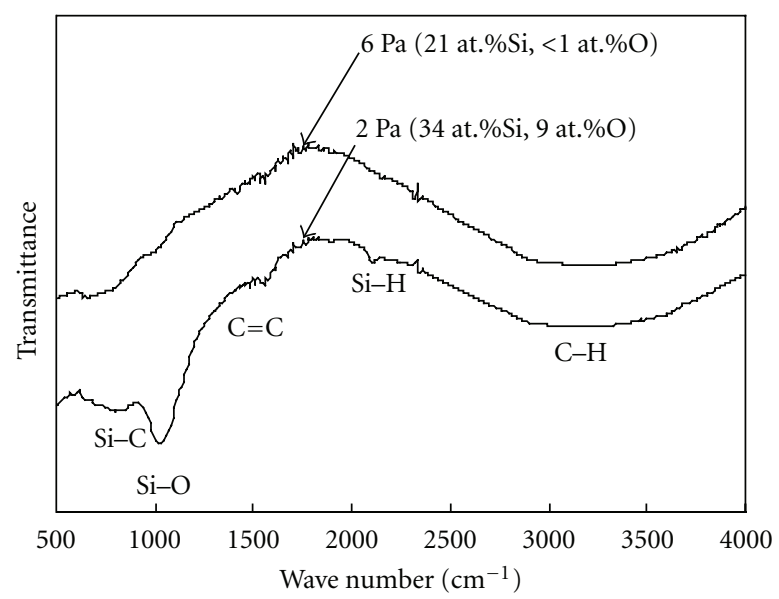

Figure 1: FT-IR spectra of DLC-Si-O films.

The DLC-Si-O films were used to investigate various annealing temperatures and atmospheres. The deposited DLC-Si-O films were annealed (held at temperature) at $400^{\circ} \mathrm{C}, 600^{\circ} \mathrm{C}$, and $750^{\circ} \mathrm{C}$ in vacuum $\left(\approx 1 \times 10^{-4} \mathrm{~Pa}\right)$, in air, and in argon atmospheres for 1 hour.

The thermal stability and tribological performance of DLC-Si-O films were studied using several characterization techniques. The chemical structure of the grown films was analyzed using the Fourier transform infrared (FT-IR) spectroscopy in the wave number range between 500 and $4000 \mathrm{~cm}^{-1}$. The structure of films was analyzed using the Raman spectroscopy (JASCO NRS-1000 DT, beam diameter $=4 \mu \mathrm{m}$, and wavelength $=532 \mathrm{~nm}$ ). The Raman spectra in the wave number of $1000-1800 \mathrm{~cm}^{-1}$ were deconvoluted into the Gaussian D and G peaks. The integral area under the $G$ and $\mathrm{D}$ peaks is determined by curve fitting. The composition at the top surface of the films was measured using energy dispersive X-ray spectroscopy (EDS). The internal stress was determined by measuring the film curvature by stylus profilometry and by applying Stoney's equation, as described in detail in the literature [20]. The tribological performance of the films was measured using a ball-on-disk friction tester (CSEM; Tribotester). In the friction test, a dry sliding test was performed using a ball indenter, AISI440C (SUS440C, diameter of $6.0 \mathrm{~mm}$ ), under a normal applied load of $3 \mathrm{~N}$, rotation radius of $3 \mathrm{~mm}$, linear speed of $31.4 \mathrm{~mm} / \mathrm{s}$, and 10,000 frictional rotations. The tests were performed under ambient air at room temperature. The area of an abraded cross-section of the wear mark was measured after friction tests to calculate specific wear rate.

\section{Results and Discussion}

3.1. Structure of the DLC-Si-O Films. The FT-IR spectra of the DLC-Si-O films before annealing are shown in Figure 1. The main absorption bands are Si-O stretching in the 1000$1100 \mathrm{~cm}^{-1}$ range, C-H stretching in the $2800-3100 \mathrm{~cm}^{-1}$ range, and $\mathrm{Si}-\mathrm{C}$ stretching in the $800 \mathrm{~cm}^{-1}$ region. A very weak $\mathrm{C}=\mathrm{C}$ stretching peak appears at around $1580 \mathrm{~cm}^{-1}$, and a $\mathrm{Si}-\mathrm{H}$ stretching peak appears in $2100 \mathrm{~cm}^{-1}$ region. It 


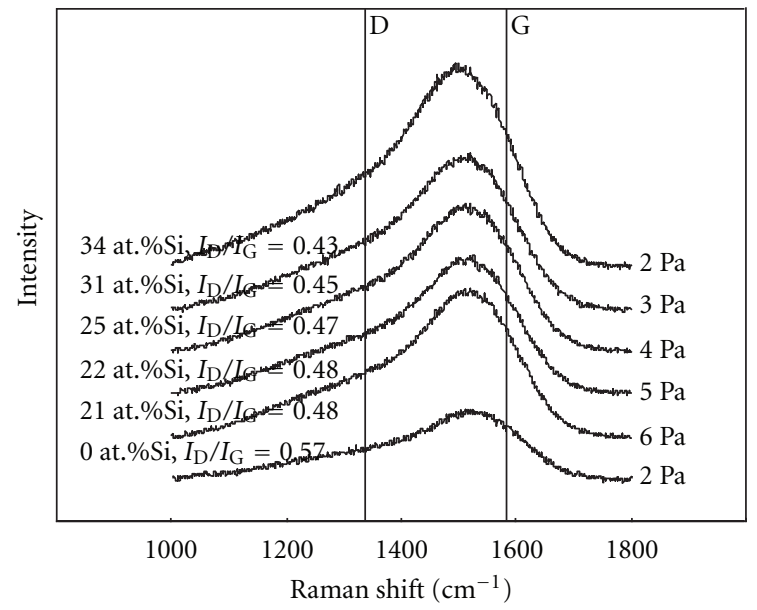

Figure 2: Raman spectra of DLC-Si-O films before annealing (as deposited).

should be noted that the $\mathrm{Si}-\mathrm{O}$ absorption band appears in the present, especially for the film at $2 \mathrm{~Pa}$ deposition pressure. The Si-O stretching peak reveals that the films deposited consist mainly of $\mathrm{Si}$ : O networks with contribution from the $\mathrm{Si}-\mathrm{C}$ bond.

The Raman spectra of the DLC-Si-O films before annealing (as deposited) are shown in Figure 2. The position of the $G$ peak is related to bond-angle disorder or $\mathrm{sp}^{3}$ bonding content, whereas the $I_{\mathrm{D}} / I_{\mathrm{G}}$ ratio is proportional to the ratio of $\mathrm{sp}^{2} / \mathrm{sp}^{3}[21,22]$. These two factors play the most important roles in determining the Raman spectra. In particular, the ratio of $\mathrm{sp}^{2} / \mathrm{sp}^{3}$ is one of the most important factors governing the quality of the DLC films. Generally, as the ratio decreases, the properties of DLC films approach the properties of diamond. The DLC-Si-O films fabricated in this experiment show a broad spectrum composed of a D peak $\left(1,350 \mathrm{~cm}^{-1}\right)$ and a $G$ peak $\left(1,580 \mathrm{~cm}^{-1}\right)$, which is similar to the peaks observed in conventional DLC films. As shown in Figure 2, the pure DLC film without Si content shows a typical diamond-like structure with a G peak at $1,535 \mathrm{~cm}^{-1}$ and an $I_{\mathrm{D}} / I_{\mathrm{G}}$ intensity ratio of 0.57 . With the increasing Si and $\mathrm{O}$ content, the G peak of films shifts from $1,530 \mathrm{~cm}^{-1}$ (21 at. $\% \mathrm{Si},<1$ at.\%O) to $1,515 \mathrm{~cm}^{-1}$ (34 at. $\% \mathrm{Si}, 9$ at. $\% \mathrm{O}$ ), while the $I_{\mathrm{D}} / I_{\mathrm{G}}$ intensity ratio decreases from 0.48 to 0.43 with silicon and oxygen incorporation. The microstructure changes result from silicon and oxygen incorporation, because the $G$ peak position shifts lower, while the $I_{\mathrm{D}} / I_{\mathrm{G}}$ intensity ratio decreases.

The $I_{\mathrm{D}} / I_{\mathrm{G}}$ intensity ratios of the DLC-Si-O films before and after annealing in vacuum, in argon, and in air atmospheres are shown in Figure 3. As shown in Figure 3(a), the $I_{\mathrm{D}} / I_{\mathrm{G}}$ ratio in the DLC-Si-O films after annealing in a vacuum started to increase at an annealing temperature of $400^{\circ} \mathrm{C}$ and then significantly increased over $600^{\circ} \mathrm{C}$ at $\mathrm{Si}$ and $\mathrm{O}$ contents to 25 at. $\% \mathrm{Si}$ and 1 at.\%O. The films at higher $\mathrm{Si}$ and $\mathrm{O}$ contents of $>25$ at. $\% \mathrm{Si}$ and $>1$ at.\%O showed an almost constant $I_{\mathrm{D}} / I_{\mathrm{G}}$ ratio until $600^{\circ} \mathrm{C}$, and the $I_{\mathrm{D}} / I_{\mathrm{G}}$ ratio significantly increased over $600^{\circ} \mathrm{C}$. Such an increase in the

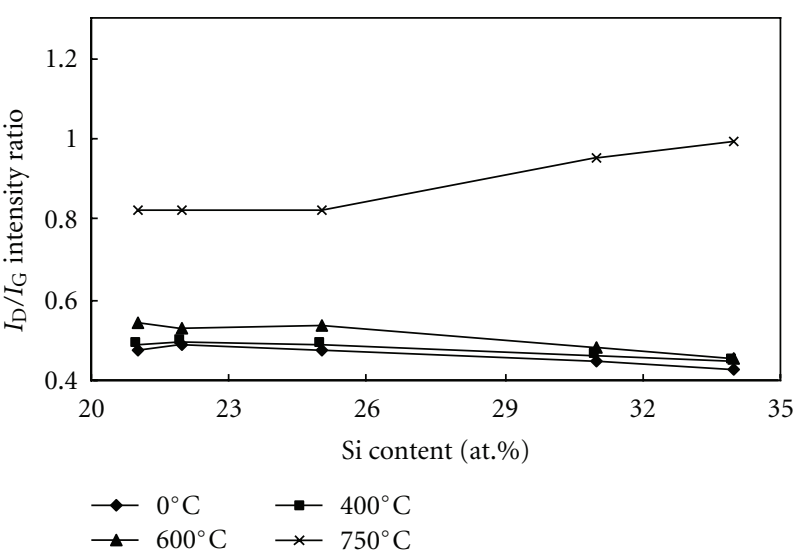

(a)

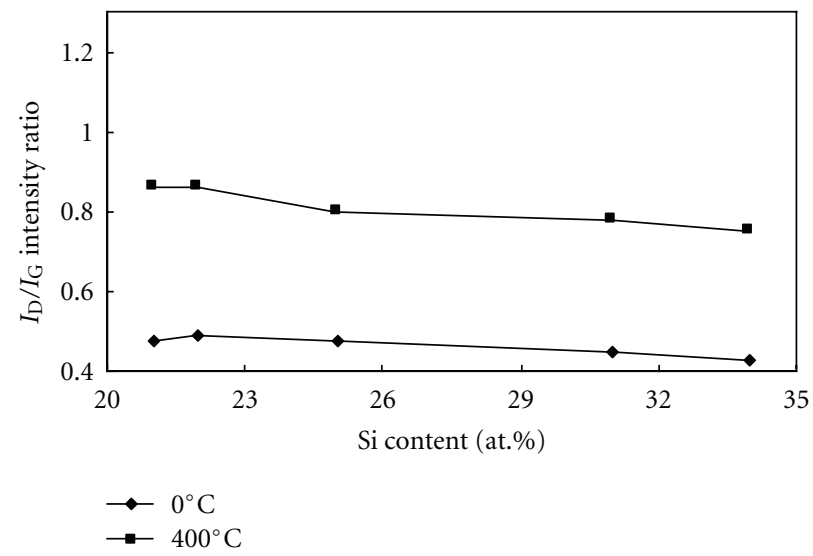

(b)

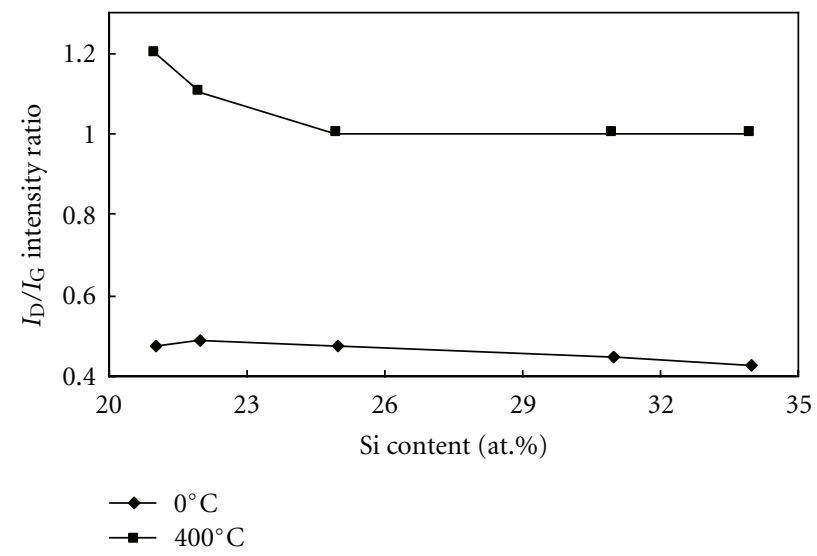

(c)

Figure 3: $I_{\mathrm{D}} / I_{\mathrm{G}}$ intensity ratio of DLC-Si-O films before and after annealing at various temperatures in (a) vacuum, (b) argon, (c) air.

$I_{\mathrm{D}} / I_{\mathrm{G}}$ ratio for the films means an increase in the number or size of graphitic domains [23]. In other words, an increase in $\mathrm{sp}^{2}$ bonds ( $\mathrm{sp}^{3}$ decreases) and the formation of $\mathrm{sp}^{2}$ clusters lead to a loss of film hardness and wear resistance. As shown in Figures 3(b) and 3(c), the $I_{\mathrm{D}} / I_{\mathrm{G}}$ ratio in the films after annealing in argon and in air both drastically increased until annealing at $400^{\circ} \mathrm{C}$, and the films were completely destroyed 
TABLE 1: Relative atomic content and internal stress of DLC-Si-O films as a function of gas flow.

\begin{tabular}{lcccccc}
\hline $\begin{array}{l}\text { Pressure } \\
(\mathrm{Pa})\end{array}$ & Gas flow $\mathrm{C}_{2} \mathrm{H}_{2}: \mathrm{TMS}: \mathrm{O}_{2}(\mathrm{sccm})$ & \multicolumn{6}{c}{ Relative atomic content (at.\%) } & Deposition rate (nm/min) & Internal stress $(\mathrm{GPa})$ \\
\hline 2 & $14: 1: 2$ & 57 & 34 & 9 & 3.0 & 0.15 \\
3 & $28: 1: 2$ & 65 & 31 & 4 & 4.4 & 0.27 \\
4 & $46: 1: 2$ & 74 & 25 & 1 & 5.3 & 0.32 \\
5 & $67: 1: 2$ & 77 & 22 & $<1$ & 7.7 & 0.25 \\
6 & $89: 1: 2$ & 78 & 21 & $<1$ & 9.2 & 0.23 \\
2 & $\mathrm{C}_{2} \mathrm{H}_{2}$ only & - & - & - & 3.3 & 2.85 \\
\hline
\end{tabular}

at $600^{\circ} \mathrm{C}$. This indicates that the graphitization of the film can be inhibited in vacuum at high annealing temperature.

In view of the above, the structures of the DLC-Si-O films with a low $\mathrm{Si}$ content $(\leq 25$ at. $\% \mathrm{Si}, \leq 1 \mathrm{at} . \% \mathrm{O})$ and high Si content $(>25$ at. $\% \mathrm{Si},>1$ at.\%O) were not affected by the thermal annealing in vacuum at $400^{\circ} \mathrm{C}$ and $600^{\circ} \mathrm{C}$, respectively, while they were affected by thermal annealing in argon and in air at $400^{\circ} \mathrm{C}$. Moreover, the graphitization in the films is drastically increased on annealing at $400^{\circ} \mathrm{C}$ in argon and in air, and the film was completely destroyed at $600^{\circ} \mathrm{C}$.

\subsection{Relative Atomic Content and Internal Stress of the DLC-} Si-O Films. Table 1 lists the measured carbon, silicon, and oxygen contents in relation to $\mathrm{C}_{2} \mathrm{H}_{2}$ gas flow, while TMS and $\mathrm{O}_{2}$ were kept constant at 1 and $2 \mathrm{sccm}$, respectively. The carbon, silicon, and oxygen concentrations measured at the top surface were measured using EDS, and values are always given in units of atomic percent (at.\%). Because hydrogen content cannot be measured using EDS, concentrations are normalized to a total of 100 at.\%, neglecting the hydrogen contribution. As the $\mathrm{C}_{2} \mathrm{H}_{2}$ gas flow increased, the deposition rate linearly increased from 3 to $9.2 \mathrm{~nm} / \mathrm{min}$, the contents of $\mathrm{C}$ in the films increased, and the content of $\mathrm{Si}$ and $\mathrm{O}$ correspondingly decreased. The variation of composition at different $\mathrm{C}_{2} \mathrm{H}_{2}$ gas flow seems to be correlated with a different decomposition rate of gaseous precursors at a given $\mathrm{C}_{2} \mathrm{H}_{2}$ gas flow. For low $\mathrm{C}_{2} \mathrm{H}_{2}$ gas flow, the molecules of TMS and $\mathrm{O}_{2}$ are easily and highly decomposed, leading to a higher fraction of $\mathrm{Si}$ and $\mathrm{O}$ content in the films. For higher $\mathrm{C}_{2} \mathrm{H}_{2}$ gas flow, however, the decomposition of $\mathrm{C}_{2} \mathrm{H}_{2}$ gas becomes active, leading to a higher fraction of $\mathrm{C}$ in the films.

For the internal stress results, the DLC-Si-O films with low $\mathrm{O}$ content $(<1$ at.\%) exhibit an internal stress increase from 0.23 to $0.32 \mathrm{GPa}$ with silicon incorporation up to 25 at.\%. It is clear that the internal stress decreases with silicon and oxygen incorporation at $>25$ at.\% $\%$ and $>1$ at. $\% \mathrm{O}$.

Figure 4 shows the relative atomic content before and after annealing in vacuum, in argon, and in air, with $2 \mathrm{~Pa}$ (34 at.\%Si, 9 at.\%O) at the top surface of DLC-Si-O films. The films annealed in vacuum showed almost constant atomic contents of $\mathrm{C}, \mathrm{Si}$, and $\mathrm{O}$ until annealing at $600^{\circ} \mathrm{C}$, and $\mathrm{O}$ content in the films started to increase at annealing temperatures over $600^{\circ} \mathrm{C}$. As shown in Figures 4(b) and 4(c), the $\mathrm{O}$ content increased, while the $\mathrm{C}$ content decreased until annealing at $400^{\circ} \mathrm{C}$, and the film was completely destroyed at $600^{\circ} \mathrm{C}$ in argon and in air. This result can be attributed to the formation of silicon oxide on the films during the thermal annealing. These results imply that oxygen from the air reacted with the Si-O network instead of carbon in the films annealed in air and in argon, and the given temperature resulted in a structural transition of the films, as mentioned earlier. In the case of annealing in air, more oxygen atoms are incorporated in the formation of silicon oxide on the films compared to annealing in argon or in vacuum. The result indicates that the $\mathrm{O}$ content increased with increasing annealing temperature, and thus the relative content of carbon decreased.

\subsection{Friction Coefficient and Wear Properties of the DLC-Si-O} Films. The friction coefficients of DLC-Si-O films measured under ambient air are shown in Figure 5.

The influence of the $\mathrm{Si}$ and $\mathrm{O}$ content on the friction coefficient of DLC-Si-O films was examined (Figure 5). The pure DLC film had an unstable friction coefficient and failed during tests, while DLC-Si-O films had a stable and lower friction coefficient and longer friction endurance due to the silicon and oxygen incorporated in the film. At Si and $\mathrm{O}$ contents of 34 at.\% $\mathrm{Si}$ and 9 at.\%O, the film is relatively stable and demonstrates a considerable improvement in tribological performance, with a friction coefficient of 0.04 . This low friction coefficient is related to the formation of silicon-rich oxide debris and the transferred layers of the silicon oxide on the steel ball surfaces [24]. The transferred silicon oxide on the steel balls that slide against the 34 at. $\% \mathrm{Si}$ and 9 at.\%O was detected by SEM, as shown in Figure 6, which depicts a micrograph of the SUS440C ball after 10,000 rotations in the friction test. The silicon oxide is shown in the white rectangular area in the figure. This silicon oxide layer prevents direct contact between the DLC-Si-O film and the ball when sliding, resulting in low friction forces. However, pure DLC film and the as-deposited DLC-Si-O film with the $\mathrm{Si}$ and $\mathrm{O}$ contents of 25 at.\%Si and 1 at.\%O exhibit a high friction coefficient due to high internal stress in the film. These data are presented in Table 1.

The friction coefficients of DLC-Si-O films after annealing in vacuum, in argon, and in air are shown in Figure 7. Both results indicate that the friction coefficient of DLC$\mathrm{Si}-\mathrm{O}$ films increased with increasing annealing temperature in vacuum, in argon, and in air. It is speculated that the film hardness decreases with increasing graphitization and 


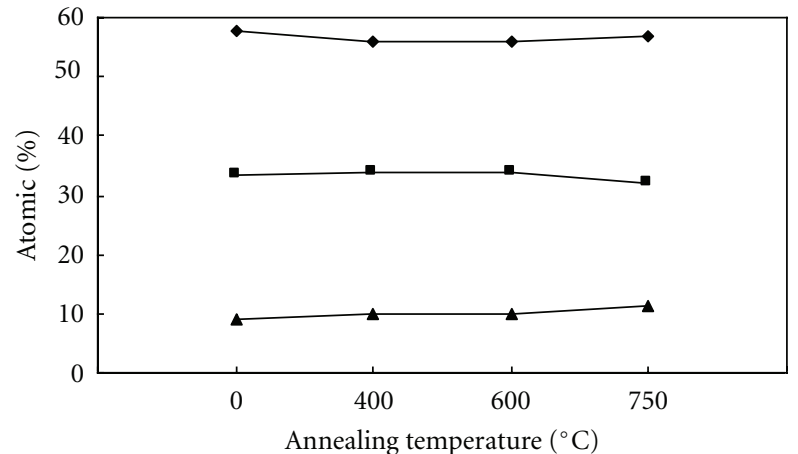

(a)

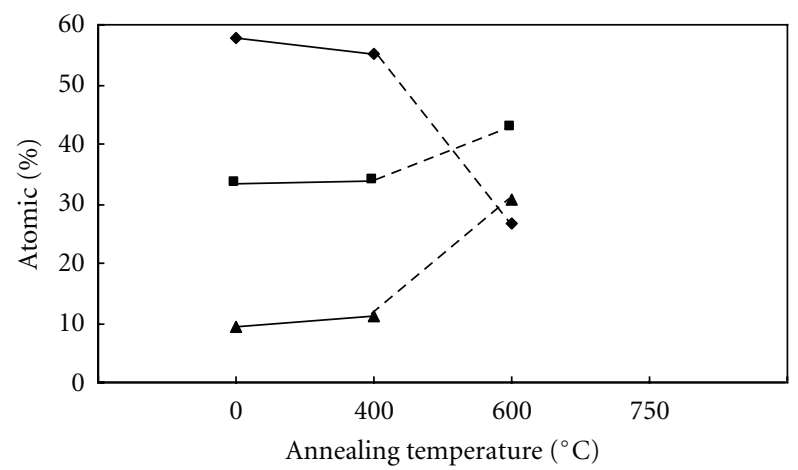

(b)

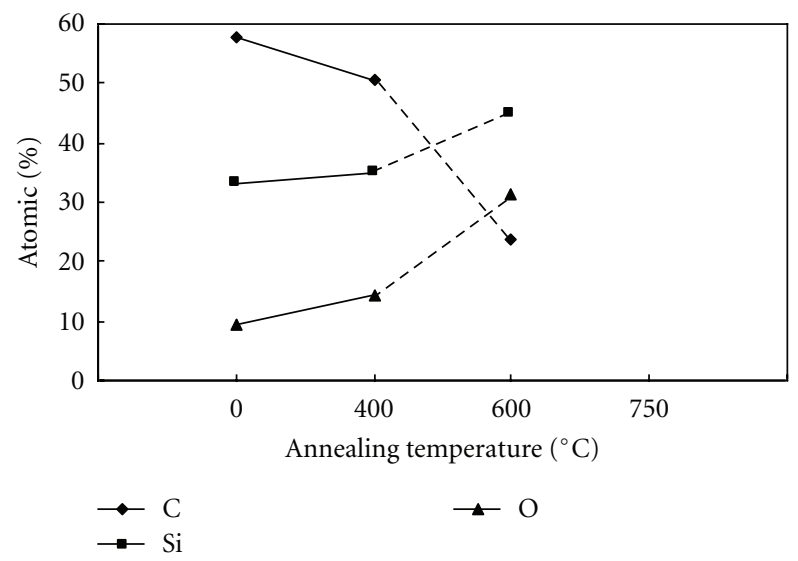

(c)

Figure 4: Relative atomic content of DLC-Si-O films with $2 \mathrm{~Pa}$ annealed in (a) vacuum, (b) argon, (c) air.

annealing temperature, as concluded from $I_{\mathrm{D}} / I_{\mathrm{G}}$ intensity ratio. In earlier studies by Yang et al. [25], it was shown that the DLC films started to be graphitized, which results in softening of the annealed film surface. The increased friction coefficient must be caused by the increased frictional force, which is the product of the contact area and the shear strength at the ball-film interface. In fact, the decreased film hardness and elastic modulus with annealing causes difficulties in supporting the load, which can increase the contact area at the ball-film interface. Hence, with a decrease of film hardness and elastic modulus and an increase in graphitization, the friction coefficient could tend

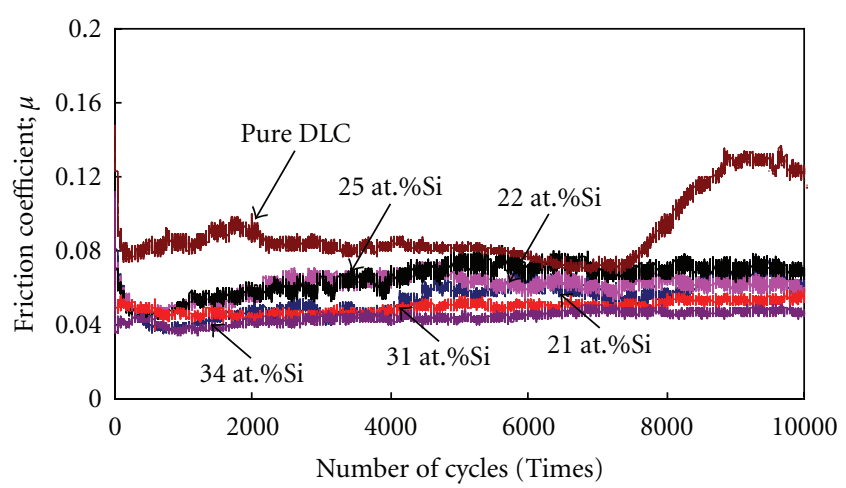

Figure 5: Changes in friction coefficients of DLC-SiO films before annealing.

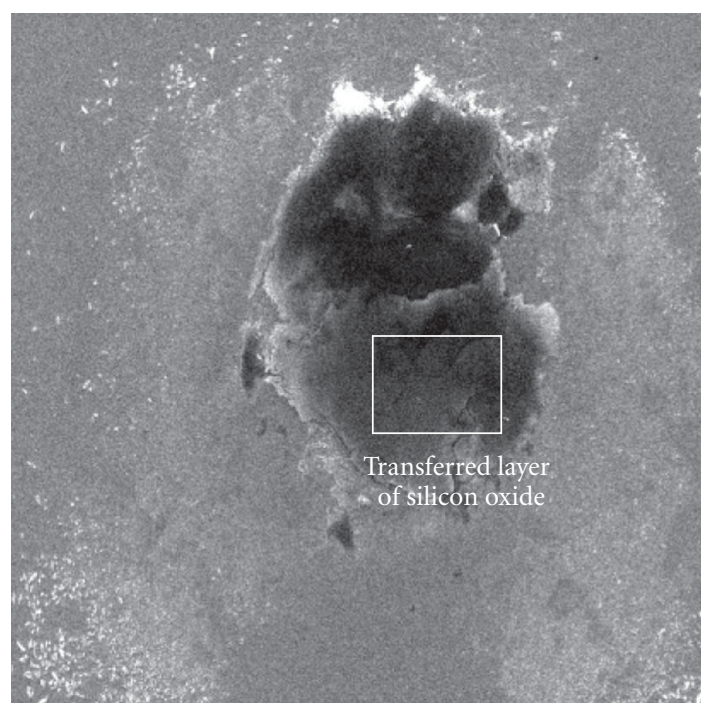

FIGURE 6: Transferred layer on SUS440C ball.

to increase. The specific wear rate results of the DLC-SiO films deposited with $2 \mathrm{~Pa}$ (34 at.\%Si, 9 at.\%O) before and after annealing in vacuum, in argon, and in air are shown in Figure 8. It is clear that the specific wear rate significantly increases with annealing in argon and in air, while it remains relatively constant until $600^{\circ} \mathrm{C}$ in vacuum. The results indicate that the friction coefficient and wear rate of DLC-Si-O films increased with increasing of the annealing temperature in argon and in air while staying constant up to $600^{\circ} \mathrm{C}$ in vacuum. Moreover, the low friction coefficient of film annealed at $600^{\circ} \mathrm{C}$ in vacuum with 34 at. $\% \mathrm{Si}$ and 9 at. $\% \mathrm{O}$ corresponds with lower film wear rate of $1.85 \times$ $10^{-7} \mathrm{~mm}^{3} / \mathrm{Nm}$.

\section{Conclusions}

The DLC-Si-O films were prepared on Si (100) wafers by the PBII method. The study investigated the effects of silicon and oxygen contents on the thermal stability and tribological performance of the films. This was accomplished by using annealing temperatures between $400^{\circ} \mathrm{C}$ and $750^{\circ} \mathrm{C}$ 


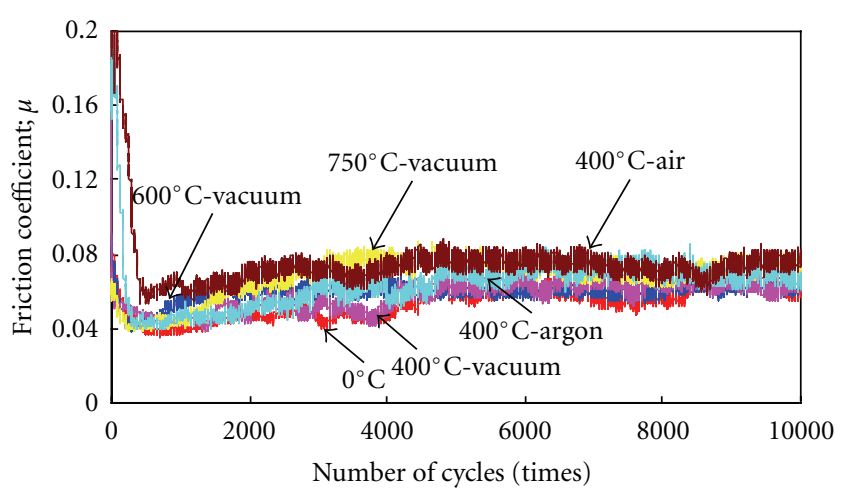

(a)

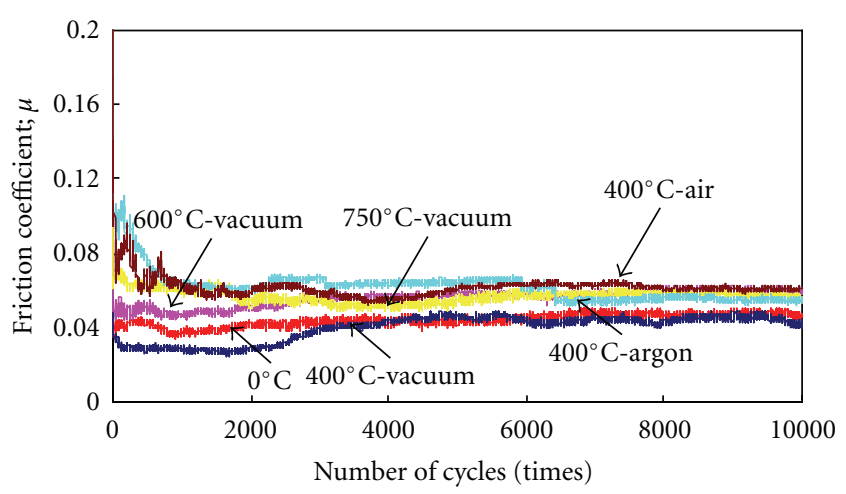

(b)

Figure 7: Changes in friction coefficients of DLC-Si-O films before and after annealing at (a) 21 at.\%Si (b) 34 at.\%Si.

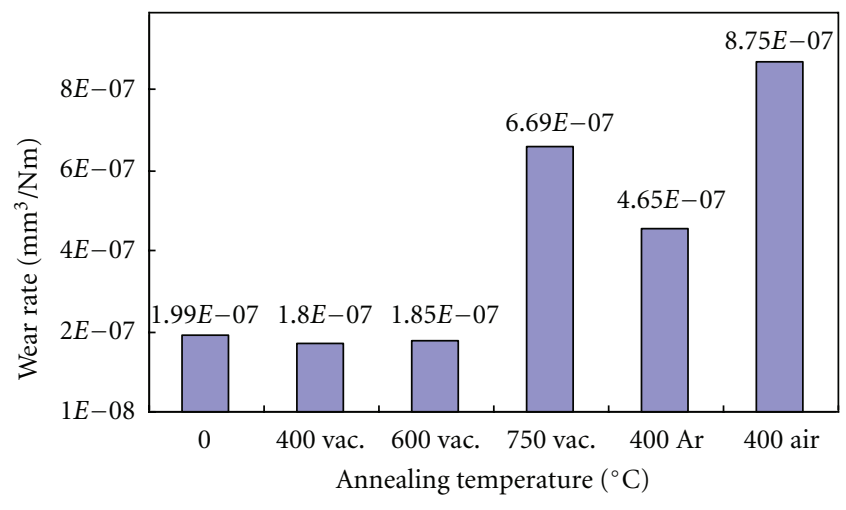

FIGURE 8: Specific wear rate of DLC-SiO films with 34 at.\%Si before and after annealing.

in vacuum, in air, and in argon atmospheres. Film properties were investigated by the Fourier transforms infrared (FT-IR) spectroscopy, the Raman spectroscopy, energy dispersive Xray spectroscopy, and a ball-on-disk friction tester. The major results obtained are as follows.

(1) FT-IR and the Raman spectra results show that the structure of the DLC-Si-O films with a low $\mathrm{Si}$ and $\mathrm{O}$ content ( $\leq 25$ at.\%Si, $\leq 1$ at.\%O) and high $\mathrm{Si}$ and $\mathrm{O}$ content ( $>25$ at. $\% \mathrm{Si}, 1>$ at.\%O) was not affected by thermal annealing in vacuum at $400^{\circ} \mathrm{C}$ and $600^{\circ} \mathrm{C}$.

(2) DLC-Si-O films with 34 at. $\%$ Si and 9 at.\%O show almost constant atomic contents until annealing at $600^{\circ} \mathrm{C}$ in vacuum. The $\mathrm{O}$ content increased, while $\mathrm{C}$ content decreased until annealing at $400^{\circ} \mathrm{C}$ and completely destroyed at $600^{\circ} \mathrm{C}$ in argon and in air, which can be attributed to the formation of silicon oxide on the films during the thermal annealing.

(3) The friction coefficient and wear properties of the DLC-Si-O films at Si and O contents of 34 at.\%Si and 9 at. $\% \mathrm{O}$ are relatively stable and demonstrate a considerable improvement in tribological performance. The friction coefficient was 0.04 before annealing and 0.05 after annealing to $600^{\circ} \mathrm{C}$ in vacuum. Moreover, the low friction coefficient of film annealed to $600^{\circ} \mathrm{C}$ in vacuum with 34 at. $\% \mathrm{Si}$ and 9 at. $\% \mathrm{O}$ corresponds with a decrease in the wear of the films of $1.85 \times$ $10^{-7} \mathrm{GPa}$.

\section{References}

[1] A. H. Lettington, "Applications of diamond-like carbon thin films," Carbon, vol. 36, no. 5-6, pp. 555-560, 1998.

[2] A. Grill and V. Patel, "Tribological properties of diamond-like carbon and related materials," Diamond and Related Materials, vol. 2, no. 5, pp. 597-605, 1993.

[3] B. Bhushan, "Chemical, mechanical and tribological characterization of ultra-thin and hard amorphous carbon coatings as thin as $3.5 \mathrm{~nm}$ : recent developments," Diamond and Related Materials, vol. 8, no. 11, pp. 1985-2015, 1999.

[4] J. Noshiro, S. Watanabe, T. Sakurai, and S. Miyake, "Friction properties of co-sputtered sulfide/DLC solid lubricating films," Surface and Coatings Technology, vol. 200, no. 20-21, pp. 5849-5854, 2006.

[5] X. He, W. Li, and H. Li, "Diamond-like carbon film synthesized by ion beam assisted deposition and its tribological properties," Journal of Vacuum Science and Technology, vol. 14, no. 4, pp. 2039-2047, 1996.

[6] J. W. Chung, D. H. Ko, K. Y. Eun, and K. R. Lee, "Elastic modulus and structural evolution of diamond-like carbon films deposited by RF-PACVD," Diamond and Related Materials, vol. 11, no. 7, pp. 1441-1446, 2002.

[7] J. X. Liao, W. M. Liu, T. Xu, and Q. J. Xue, "Characteristics of carbon films prepared by plasma-based ion implantation," Carbon, vol. 42, no. 2, pp. 387-393, 2004.

[8] R. O. Dillon, J. A. Woollam, and V. Katkanant, "Use of Raman scattering to investigate disorder and crystallite formation in as-deposited and annealed carbon films," Physical Review B, vol. 29, no. 6, pp. 3482-3489, 1984.

[9] J. C. Damasceno, S. S. Camargo Jr., F. L. Freire Jr., and R. Carius, "Deposition of Si-DLC films with high hardness, low stress and high deposition rates," Surface and Coatings Technology, vol. 133-134, pp. 247-252, 2000.

[10] W. J. Yang, T. Sekino, K. B. Shim, K. Niihara, and K. H. Auh, "Microstructure and tribological properties of $\mathrm{SiO}_{x} / \mathrm{DLC}$ films grown by PECVD," Surface and Coatings Technology, vol. 194, no. 1, pp. 128-135, 2005. 
[11] J. Choi, S. Nakao, S. Miyagawa, M. Ikeyama, and Y. Miyagawa, "The effects of Si incorporation on the thermal and tribological properties of DLC films deposited by PBII\&D with bipolar pulses," Surface and Coatings Technology, vol. 201, no. 19-20, pp. 8357-8361, 2007.

[12] C. Venkatraman, C. Brodbeck, and R. Lei, "Tribological properties of diamond-like nanocomposite coatings at high temperatures," Surface and Coatings Technology, vol. 115, no. 2-3, pp. 215-221, 1999.

[13] J. Choi, S. Miyagawa, S. Nakao, M. Ikeyama, and Y. Miyagawa, "Thermal stability of diamond-like carbon films deposited by plasma based ion implantation technique with bipolar pulses," Diamond and Related Materials, vol. 15, no. 4-8, pp. 948-951, 2006.

[14] J. R. Conrad and T. Castagna, "Plasma source ion implantation for surface modification," Bulletin of the American Physical Society, vol. 31, p. 1479, 1986.

[15] L. Xia, M. Sun, and J. Liao, "The effect of negative bias pulse on the bonding configurations and properties of DLC films prepared by PBII with acetylene," Diamond and Related Materials, vol. 14, no. 1, pp. 42-47, 2005.

[16] J. R. Conrad, J. L. Radtke, R. A. Dodd, F. J. Worzala, and N. C. Tran, "Plasma source ion-implantation technique for surface modification of materials," Journal of Applied Physics, vol. 62, no. 11, pp. 4591-4596, 1987.

[17] A. H. Jayatissa, F. Sato, N. Saito, Y. Hirano, and K. Takizawa, "Characterization of diamond-like carbon clusters deposited by pulsed ArF laser deposition," Carbon, vol. 38, no. 8, pp. 1145-1151, 2000.

[18] J. X. Liao, W. M. Liu, T. Xu et al., "Structures and tribological properties of diamond-like carbon films prepared by plasmabased ion implantation on Si," Surface and Coatings Technology, vol. 191, no. 1, pp. 90-95, 2005.

[19] N. Moolsradoo and S. Watanabe, "Deposition and tribological properties of sulfur-doped DLC films deposited by PBII method," Advances in Materials Science and Engineering, vol. 2010, Article ID 958581, 7 pages, 2010.

[20] L. G. Jacobsohn and F. L. Freire Jr., "Influence of the plasma pressure on the microstructure and on the optical and mechanical properties of amorphous carbon films deposited by direct current magnetron sputtering," Journal of Vacuum Science and Technology A, vol. 17, no. 5, pp. 2841-2849, 1999.

[21] J. Qi, J. B. Luo, S. Z. Wen, J. Wan, and W. Z. Li, "Mechanical and tribological properties of non-hydrogenated DLC films synthesized by IBAD," Surface and Coatings Technology, vol. 128-129, pp. 324-328, 2000.

[22] M. A. Capano, N. T. McDevitt, R. K. Singh, and F. Qian, "Characterization of amorphous carbon thin films," Journal of Vacuum Science and Technology A, vol. 14, no. 2, pp. 431-435, 1996.

[23] F. L. Freire Jr., G. Mariotto, R. S. Brusa, A. Zecca, and C. A. Achete, "Structural characterization of amorphous hydrogenated carbon and carbon nitride films deposited by plasma-enhanced CVD," Diamond and Related Materials, vol. 4, no. 4, pp. 499-502, 1995.

[24] S. H. Yang, H. Kong, K. R. Lee, S. Park, and D. E. Kim, "Effect of environment on the tribological behavior of Siincorporated diamond-like carbon films," Wear, vol. 252, no. 1-2, pp. 70-79, 2002.

[25] W. J. Yang, Y. H. Choa, T. Sekino, K. B. Shim, K. Niihara, and K. H. Auh, "Thermal stability evaluation of diamond-like nanocomposite coatings," Thin Solid Films, vol. 434, no. 1-2, pp. 49-54, 2003. 

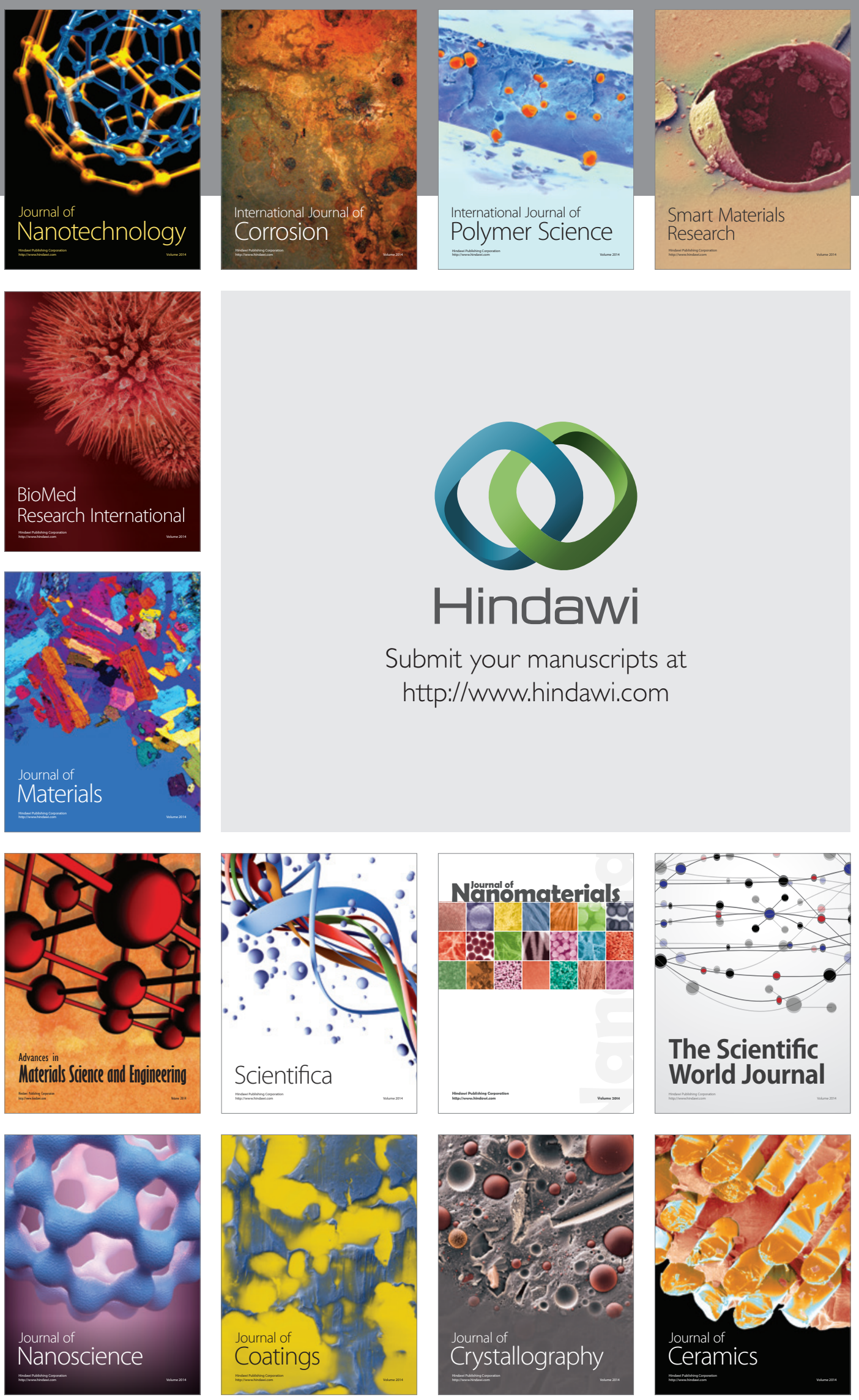

The Scientific World Journal

Submit your manuscripts at

http://www.hindawi.com

\section{World Journal}

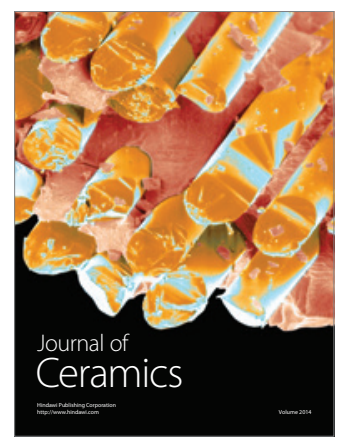

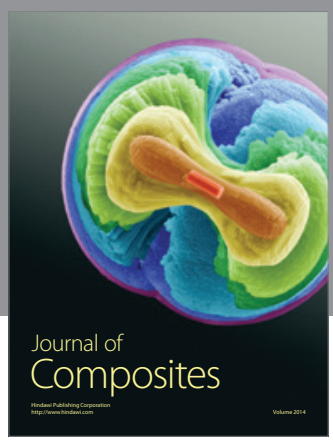
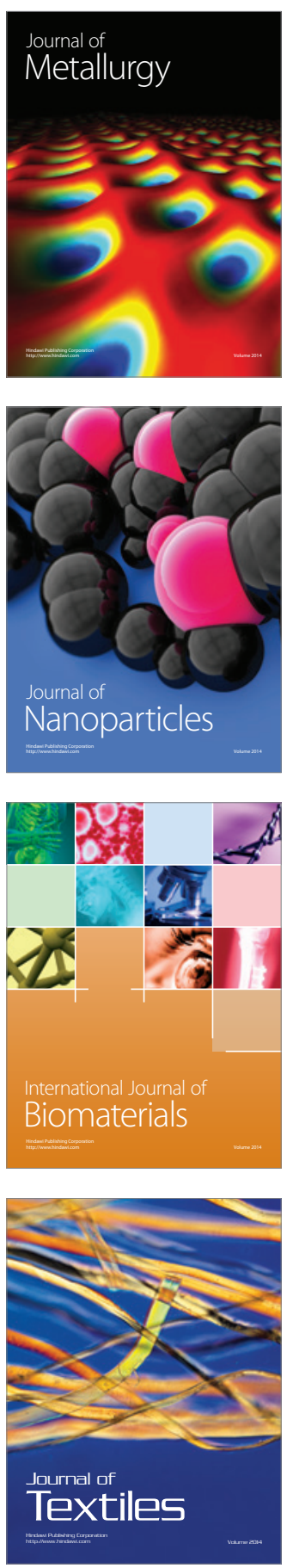